\title{
Symptomatic asymmetry in the first six months of life: differential diagnosis
}

\author{
Jacqueline Nuysink • Ingrid C. van Haastert • \\ Tim Takken • Paul J. M. Helders
}

Received: 11 October 2007 /Revised: 27 January 2008 / Accepted: 29 January 2008 /Published online: 4 March 2008

(C) The Author(s) 2008

\begin{abstract}
Asymmetry in infancy is a clinical condition with a wide variation in appearances (shape, posture, and movement), etiology, localization, and severity. The prevalence of an asymmetric positional preference is $12 \%$ of all newborns during the first six months of life. The asymmetry is either idiopathic or symptomatic. Pediatricians and physiotherapists have to distinguish symptomatic asymmetry (SA) from idiopathic asymmetry (IA) when examining young infants with a positional preference to determine the prognosis and the intervention strategy. The majority of cases will be idiopathic, but the initial presentation of a positional preference might be a symptom of a more serious underlying disorder. The purpose of this review is to synthesize the current information on the incidence of SA, as well as the possible causes and the accompanying signs that differentiate SA from IA. This review presents an overview of the nine most prevalent disorders in infants in their first six months of life leading to SA. We have discovered that the literature does not provide a comprehensive analysis of the incidence, characteristics, signs, and symptoms of SA. Knowledge of the presented clues is important in the clinical decision making with regard to young infants with asymmetry. We recommend to design a valid and useful screening instrument.
\end{abstract}

J. Nuysink $(\bowtie) \cdot$ T. Takken $\cdot$ P. J. M. Helders

Department of Pediatric Physical Therapy \& Exercise Physiology, Wilhelmina Children's Hospital, University Medical Center, KB 02.056.0, P.O. Box 85090, 3508 AB Utrecht, The Netherlands e-mail: j.nuysink@umcutrecht.nl

I. C. van Haastert

Department of Neonatology, Wilhelmina Children's Hospital, University Medical Center,

Utrecht, The Netherlands
Keywords Infant · Symptomatic asymmetry · Etiology · Differential diagnosis $\cdot$ Screening $\cdot$ Torticollis .

Plagiocephaly
Abbreviations
SA Symptomatic asymmetry
IA Idiopathic asymmetry
DP Deformational plagiocephaly
CMT Congenital muscular torticollis
CP Cerebral palsy

\section{Introduction}

The objective of this descriptive review is to determine and classify the possible causes of asymmetry seen in young infants who have an asymmetric head and/or body posture, as well as to present an overview of the nine most prevalent disorders in infants in the first six months of life leading to the diagnosis of symptomatic asymmetry (SA). Asymmetric infants form an increasing and complicated group of children seen by professionals from various clinical specialties, such as well baby clinic physicians, pediatricians, pediatric physiotherapists, orthopedic surgeons, and plastic surgeons $[4,6,19,37,50,61]$. Asymmetry in infancy is a mostly benign symptom, but in this early phase of life, the differential diagnostics are extensive. The background of the professional influences the way in which associated clinical problems are evaluated. A screening instrument would be helpful. The first step in this process is to synthesize the current information in the literature about differential diagnostics.

Twelve percent of all Dutch newborns develop a positional preference in the first few months of life, 
different from the physiological asymmetry [6]. A "positional preference" is defined as a condition in which the infant's head is turned toward one side most of the time and active movement to the other side is restricted $[4,6]$. About $25 \%$ of these infants (approximately 5,000 a year in the Netherlands) are referred to pediatric physical therapists [6]. Asymmetry in infancy is a clinical condition with a wide variation in appearances (shape, posture, and movement), etiology, localization, and severity. From the referred infants, the asymmetry is either idiopathic or symptomatic, and originates ante- and/or postpartum [37, 48, 50, 51, 61]. In case of an idiopathic asymmetry (IA), the etiology is uncertain; environmental factors play a major role in the development of the asymmetry [6, 34, 35, 48, 62]. In SA, an underlying disorder, disease, or dysfunction causes the asymmetry. The majority of cases will be idiopathic, but an initial presentation of positional preference might be a symptom of a serious underlying problem. In the last decade, many studies on the appearances of IA have been published. If the focus in diagnostics and pattern recognition is on IA, there is a chance that an SA will be missed [3, 20]. When examining young infants with a positional preference, differentiating SA from IA is necessary to determine the prognosis and to choose appropriate intervention strategies.

This review will address the following question: which diagnoses, incidence rates, signs, and symptoms are described in the literature and are thought to cause a symptomatic asymmetrical posture or movement pattern in infants during their first six months of life?

\section{Methods}

\section{Search strategy}

This review is based on a comprehensive literature search on SA. The following strategy is used: peer-reviewed literature on this topic in journals with a science citation index was searched, as well as clinical textbooks from the various clinical specialties. Computerized bibliographic databases were searched (PubMed, Pedro, Cinahl, and Cochrane Controlled Trials Register), and related papers and their references. General keywords used were: asymmetry, plagiocephaly, torticollis, posture, scoliosis, (differential) diagnosis, and screening. The search then focused on specific diagnoses that might cause asymmetry in infancy condition with the keywords: etiology, tumors, disorders (related to) vision, hearing, central nervous, or musculoskeletal system, obstetric complications, brachial plexus palsy/lesion, clinical syndromes (Grisel, Sandifer), congenital anomalies and syndromes, gastroesophageal reflux, developmental dysplasia of the hip, paroxysmal torticollis, (birth) trauma, and clavicle fracture. Finally, we focused on the incidence and prevalence. The search was limited to citations that included: "all infants, birth-23 months," had an abstract, were written in English, and the search terms were in the title or abstract. The year of publication was not restricted. When more papers on the same subject were found, the most current studies were chosen. Only diagnoses that could be observed in infants in the first six months of life were included. Unique case reports and innocuous abnormalities that require no specific treatment were not included.

\section{Results}

The prevalence and/or incidence of the various medical diagnoses leading to SA was not always documented. Some disorders had no consistency in their reported incidence rates. The majority of children with a positional preference or asymmetry during the first six months of life are diagnosed with an IA $[4,6,34,35,37,48,50,51]$. Table 1 shows a selection of the most frequently detected disorders causing an SA.

In the last decade, discussion on positional preference leading to deformational plagiocephaly (DP) has increased substantially. A relatively high number of hits found during a search in January 2008 within PubMed resulted in the following: asymmetry (811), plagiocephaly (206), torticollis (225), posture (405), and scoliosis (623). However, when combined with "differential diagnosis" or "screening," the result decreased to less than 20 each. Differential diagnosis from craniosynostosis was often described [24, 33, 36, 51]. The main designs were retrospective or prospective descrip-

Table 1 Disorders related to symptomatic asymmetry (SA) from the literature search

\begin{tabular}{ll}
\hline Disorders with known incidence & Incidence/1,000 \\
1. Developmental dysplasia of the hip (DDH) & 40 \\
2. Perinatal fracture of the clavicle & 35 \\
3. Congenital muscular torticollis (CMT) & 20 \\
4. Obstetric brachial plexus palsy & 4 \\
5. Central nervous system disorders & 2 \\
6. Craniosynostosis/lambdoid suture & 0.03 \\
Remaining groups of disorders & \\
7. Congenital abnormalities or malformations \\
Musculoskeletal \\
Chromosomal \\
8. Sensory systems \\
Ocular disorders \\
Hearing disorders \\
9. Acquired asymmetry postpartum in one of the \\
remaining systems (non musculoskeletal)
\end{tabular}


tive studies and reviews. In diagnoses with a low incidence, the studies were predominantly case reports.

All diagnoses were classified according to the International Classification of Diseases [1]. The results of the literature search are presented below, starting with the diagnosis with the highest incidence rate.

Developmental dysplasia of the hip

Developmental dysplasia of the hip (DDH) has a high rate of co-morbidity with congenital muscular torticollis (8$20 \%$ ) [11] and, to a lesser extent, with postural torticollis or scoliosis [50]. The reported incidence rate in the Netherlands ranged from 3 to $4 \%$ of all newborns [4, 11, 48], with $80 \%$ being unilateral $[5,56]$. The clinical signs which are described include asymmetry in hip abduction and leg length and/or asymmetrical skin folds in the inguinal and upper thigh region. The strong association with other asymmetries warrants a thorough screening on the signs of developmental dysplasia of the hip in infants with an asymmetry.

Perinatal fracture of the clavicle

A fracture of the clavicle during birth may induce a positional preference in the first weeks of life and, as such, may cause an asymmetry. A perinatal fracture can be an option in the differential diagnostics of asymmetry during the first weeks of life. A co-incidence with other perinatal injuries (like brachial plexus injury) was described by Perlow et al. [49]. The obstetric brachial plexus lesion is described separately. The incidence varies between 0.1 and $3.5 \%$ [28, 40, 49, 54], and these fractures usually consolidate within 3 weeks without complications. The clinical presentation can be asymptomatic. When symptomatic, signs include: decreased or absent movement and pain, or tenderness on movement of the arm on the affected side and palpable irregularity along the clavicle [54].

\section{Congenital muscular torticollis}

Congenital muscular torticollis (CMT) is frequently described in the literature. Unilateral fibrosis or thickening of and tightness in the sternocleidomastoid muscle can cause a characteristic posture of the head and restricted neck movements. The etiology of the pseudo-tumor or mass is unclear $[10,11,19,58]$. A compartment syndrome due to intra-uterine malposition is the most frequently mentioned etiological hypothesis $[10,12,19,39]$. An association with birth trauma and breech presentation is mentioned, but the evidence is weak, since CMT is also seen in infants born via a cesarean section $[11,32]$. A pseudo-tumor can be palpated in the second or third week after birth. Incidence rates of CMT vary between 0.3 and $2 \%[10-12,19,58]$. Ultrasound screening soon after birth has indicated that the incidence rate could be $3.9 \%$. This screening method tends to be especially sensitive in detecting occult cases of fibrosis [10].

Fibroids of the uterus and other intrauterine tumors are described as a possible etiology to an atrophy of the sternocleidomastoid muscle of the child [18]. This phenomenon can cause a unilateral muscular dysfunction and a strong imbalance between both muscles. The distinction between CMT and postural torticollis is not always clear [15]. A CMT is primarily a condition with a structural fibroid shortening of the sternocleidomastoid muscle, visible and palpable in the first weeks of life, as opposed to a postural torticollis that occurs secondary to a positional preference and a DP $[6,37,48,51,61]$.

\section{Obstetric brachial plexus palsy}

Palsy of the brachial plexus during delivery is caused by traction or compression of the plexus during labor. In most cases, the upper brachial plexus is affected; in $15 \%$ of the patients, hand function is also impaired. The described incidence is $0.1-0.4 \%[31,49,52]$. The extent of the neural damage becomes evident during the first six months of life [52], although in severe cases, the inactivity of the extremity is observed from birth onwards. Timely recognition of severe cases is important, since neurosurgical intervention can enhance future capacities. Between 20 and $25 \%$ of the infants experience persistent functional impairments [31].

\section{Central nervous system disorders}

Cerebral palsy (CP) syndromes, in particular, spastic unilateral $\mathrm{CP}$, are neurological disorders that can cause asymmetry [3,7]. Serious disorders of the central nervous system are generally easy to recognize, but a CP may also be discrete with subtle features. Early diagnosis, before the age of six months, might be difficult [45, 57]. The neurodevelopmental (motor) behavior is an important issue in early recognition: persistent infantile reflexes and abnormal muscle tone, motor delay, abnormal spontaneous movement patterns (especially "general movements"), and poor postural control are more or less predictors of $\mathrm{CP}[25,45,46]$. In a review on the epidemiology of $\mathrm{CP}$, the world-wide prevalence of all types of CP is estimated at $0.2 \%$ [43].

Hypotonia and developmental delay were also mentioned as causes for developing positional preference and DP. A neurological disorder might be the underlying problem, but it is not always diagnosed at this young age $[3,7,51]$. 


\section{Craniosynostosis}

Craniosynostosis, the premature fusion of one or more cranial sutures, is most frequently described in relation to asymmetry and plagiocephaly, possibly as a result of the over-referral of infants with deformational non-synostotic DP to craniofacial or plastic surgery clinics. Primary craniosynostosis is either simple or compound and part of a genetic syndrome [36]. Premature closing of one lambdoid suture is the most frequently mentioned differential diagnosis of DP $[24,33,36]$. The incidence of this single suture craniosynostosis is rare (1-3 cases to 100,000 newborns) [37, 42] and can be clinically differentiated from DP by four major signs: from the vertex view, a trapezoid head shape can be observed, a palpable unilateral ridge, bulging of the unilateral mastoid, and an asymmetric skull base with tilt to the ipsilateral side [24, $33,42]$. The impact of the premature closure of cranial sutures in complex craniosynostosis is impressive: strong progressive deformation of the skull, risk of increasing intracranial pressure, and developmental problems. When evident, timely surgical intervention is warranted [24, 33, $36,50,51]$.

The following three categories are groups of disorders. Clear incidence rates could not be found.

\section{Congenital abnormalities or malformations}

Musculoskeletal congenital malformations must be considered in an asymmetry that is present immediately after birth $[3,7]$. Well-known malformations are those of the spine, such as a Klippel-Feil syndrome, hemi-vertebrae, and a hemi-atlas [22, 38, 64]. Exceptional phenomena are hypoplasia or aplasia of the face, neck, or trunk muscles [2]. Patients may show defects in other systems as well, such as syndactyly, deafness, or a congenital heart disease. The co-incidence of defects may be an important sign of a syndrome. An asymmetric development or posture can be an associated finding in a variety of syndromes and abnormalities. These features are often present immediately after birth, but will not always be discovered until a second stage [64]. Local abnormalities, such as a vascular ring (around the trachea) or tracheomalacia, are occasionally an indirect cause of an asymmetric posture [60].

\section{Disorders in sensory systems}

In the screening of infants with asymmetry, eye movement and/or vision and hearing disorders must be considered. Infants with congenital nystagmus and restrictive or paralytic strabismus may use anomalous head positions to maximize visual function $[26,47,63]$. No clear incidence rates were found. A predictive factor for an ocular origin of torticollis is the family history of ocular problems, in particular, congenital nystagmus. The ocular pathology may be subtle. In case of doubt, infants must be referred to an ophthalmologist [63].

Theoretically, a unilateral hearing disorder can induce a positional preference in young infants. In the literature search, no match was found for hearing loss and torticollis, except in syndromes such as Klippel-Feil or Moebius. A connection between ear malformation and hearing loss is mentioned [23].

Acquired asymmetry, non-musculoskeletal

A number of disorders in systems other than the musculoskeletal system can cause a postpartum asymmetry, but the asymmetry is not the only symptom. The disorders have in common that their symptoms are not stable and occur some time after birth. The signs and symptoms can be seen as so-called "red flags" and require immediate medical evaluation. It may be secondary to a trauma [27] or to inflammatory conditions, such as pharyngitis [8, 13, 29, 55]. Grisel syndrome (a nontraumatic atlanto-axial rotatory subluxation following infections of the upper respiratory tract) is often described, but never under the age of six months [7, 19, 29]. Another cause can be related to the cardio-respiratory or the digestive system, such as Sandifer syndrome (fluctuating asymmetry with abnormal body movements and contor-

Table 2 Signs and symptoms of acquired symptomatic asymmetry disorders with a low incidence

\begin{tabular}{ll}
\hline Signs and symptoms & Hints for disorders \\
\hline General history & \\
Heavy pain & Retro-pharyngeal abscess [13] \\
Vomiting/drowsiness & Increased intracranial pressure [30] \\
Lethargy/irritability & Tumor [12, 30], intracranial injury [27] \\
Trauma & Intracranial injury [27] \\
Seizures/convulsions & Epilepsy; increased intracranial pressure; \\
& Sandifer syndrome [17] \\
Acute onset & Infection, abscess [13]; Grisel syndrome \\
& (>6 months) [29, 55] \\
Stridor, dyspnea & Vascular ring [60] \\
Reflux & Sandifer syndrome; pathological \\
& gastroesophageal reflux [17] \\
Fever & Infection, abscess [13] \\
Specific examination & \\
Sunset phenomenon & Increased intracranial pressure \\
Bulging anterior fontanel & Increased intracranial pressure, \\
& intracranial injury [27] \\
Abnormal course & \\
Increasing head tilt & Infection [13]; tumor [12, 30] \\
Recurrent episodes & Benign paroxysmal torticollis [9, 21] \\
\hline
\end{tabular}


tions of the neck, associated with gastroesophageal reflux) $[9,17,21]$. The most alarming causes of asymmetry are related to neurological syndromes, such as syringomyelia, epilepsy, high intracranial pressure, postencephalitic syndromes, or life-threatening tumors of the central nervous system $[3,7,12,19,20,30]$. These disorders are mainly described in case studies, without proven incidence rates. The signs and symptoms of these non-musculoskeletal causes are described in Table 2.

\section{Discussion}

Asymmetry in infancy is a condition with a high prevalence in infants in the first six months of life. In the majority of cases, the origin is idiopathic and is often related to environmental factors $[6,15,34,35,37,62]$. This review addresses the possible causes, incidence rates, and symptoms of symptomatic asymmetries due to an underlying disorder, dysfunction, or disease.

Not all of the incidence rates could be found, while some inconsistencies were observed in the current literature. The disorders with a high prevalence are well described in epidemiologic studies. The rarer diseases were, most of the time, documented in case reports without incidence rates. The incidence rates mentioned in the studies are inconsistent because of different opinions regarding the operationalization and assessment of the SA. Frequently, psychometric properties of instruments and concepts have not been described or evaluated. Variations in incidence rates (e.g. CMT) are inevitable, considering the variety in inclusion criteria and diagnostic tests used in the studies. The sequence in estimated incidence rates, as proposed in Table 1 , is open to debate.

A clear description of signs and symptoms was not always presented in the literature. The variety in the etiology of asymmetry is considerable. The level of evidence of the included studies varies. Literature of more than 10 years ago mainly described underlying causes of SA, in particular, non-muscular torticollis [3, 7]. They still turned out to be useful in establishing criteria for differential diagnostic screening and are widely cited in current studies. However, an update regarding new developments in studies on infant asymmetry is needed. The exponential increase of plagiocephaly in the last decade, related to the recommendations to put babies on their back to sleep, is reflected in the objectives of recent studies $[4,6,37,41]$. They mainly focused on IA and its predispositions, with little attention to SA. A number of recent papers described features to distinguish craniosynostosis from DP. Although craniosynostosis has a very low incidence, craniofacial clinics are deluged with infants with DP $[14,15,37]$. One of the positive effects of this situation is that authors from this background described useful clinical diagnostic criteria for craniosynostosis.

van Vlimmeren et al. [61] stated in their review on diagnostic strategies, that asymmetry in infancy is a diagnosis with a large spectrum of features and a multifactorial etiology without consensus on definition, nomenclature, or classification. In the present review, a classification by virtue of etiology is proposed. The dichotomy, symptomatic versus idiopathic, is often used in medicine $[16,44,53$, 59] and fits well with this health problem, since a large number of children have unexplained asymmetry.

Although flow diagrams for diagnostic strategies are presented in some reviews [3, 7, 15, 19,61], clear clinical diagnostic criteria that could be used were not mentioned. The criteria found in the present review might be considered in a future study. An expert validation, such as a Delphi study with clinical experts, could be a next step towards establishing clinical diagnostic criteria as warning flags in young infants with IA or SA.

This review presents an overview of the most common disorders underlying SA in infants less than six months of age. We have discovered that the literature does not provide a comprehensive analysis of the incidence, characteristics, signs, and symptoms of SA. Knowledge of the presented clues is important in the clinical decision making with regard to young infants with asymmetry. The endpoint of this review may be a starting document for the creation of a protocol, but it needs additional studies in order for it to become a valid and useful screening instrument.

Acknowledgments We like to thank Raoul H. H. Engelbert, $\mathrm{PhD}$, PCS, PT, Associate Professor, Amsterdam School for Health Professions, Amsterdam, the Netherlands, for his substantive comments.

Open Access This article is distributed under the terms of the Creative Commons Attribution Noncommercial License which permits any noncommercial use, distribution, and reproduction in any medium, provided the original author(s) and source are credited.

\section{References}

1. World Health Organization (2007) International Classification of Diseases (ICD), part 1, 10th edn. Available online at: http://www. who.int/classifications/apps/icd/icd10online/

2. Adams SB Jr, Flynn JM, Hosalkar HS, Hunter J, Finkel R (2003) Torticollis in an infant caused by hereditary muscle aplasia. Am J Orthop 32:556-558

3. Ballock RT, Song KM (1996) The prevalence of nonmuscular causes of torticollis in children. J Pediatr Orthop 16:500-504

4. Boere-Boonekamp MM, Bunge-van Lent FCGM, Roovers EA, Haasnoot-Smallegange ME (2005) Positional preference in infants: prevalence, prevention and care. T Jeugd Gez Zorg 5:92-97

5. Boere-Boonekamp MM, Kerkhoff TH, Schuil PB, Zielhuis GA (1998) Early detection of developmental dysplasia of the hip in The Netherlands: the validity of a standardized assessment protocol in infants. Am J Public Health 88:285-288 
6. Boere-Boonekamp MM, van der Linden-Kuiper LT (2001) Positional preference: prevalence in infants and follow-up after two years. Pediatrics 107:339-343

7. Bredenkamp JK, Hoover LA, Berke GS, Shaw A (1990) Congenital muscular torticollis. A spectrum of disease. Arch Otolaryngol Head Neck Surg 116:212-216

8. Brisson P, Patel H, Scorpio R, Feins N (2000) Rotary atlanto-axial subluxation with torticollis following central-venous catheter insertion. Pediatr Surg Int 16:421-423

9. Chaves-Carballo E (1996) Paroxysmal torticollis. Semin Pediatr Neurol 3:255-256

10. Chen MM, Chang HC, Hsieh CF, Yen MF, Chen TH (2005) Predictive model for congenital muscular torticollis: analysis of 1021 infants with sonography. Arch Phys Med Rehabil 86:2199-2203

11. Cheng JC, Au AW (1994) Infantile torticollis: a review of 624 cases. J Pediatr Orthop 14:802-808

12. Constantini S, Houten J, Miller DC, Freed D, Ozek MM, Rorke LB, Allen JC, Epstein FJ (1996) Intramedullary spinal cord tumors in children under the age of 3 years. J Neurosurg 85:1036-1043

13. Craig FW, Schunk JE (2003) Retropharyngeal abscess in children: clinical presentation, utility of imaging, and current management. Pediatrics 111:1394-1398

14. David DJ, Menard RM (2000) Occipital plagiocephaly. Br J Plast Surg 53:367-377

15. de Chalain TM, Park S (2005) Torticollis associated with positional plagiocephaly: a growing epidemic. J Craniofac Surg $16: 411-418$

16. Degen R, Degen HE, Roth C (1990) Some genetic aspects of idiopathic and symptomatic absence seizures: waking and sleep EEGs in siblings. Epilepsia 31:784-794

17. Deskin RW (1995) Sandifer syndrome: a cause of torticollis in infancy. Int J Pediatr Otorhinolaryngol 32:183-185

18. Dimitrov A, Bosev D, Nikolov A, Stoianov S (2003) Submucosal isthmicocervical myoma-problems of diagnosis, labor and puerperium. Akush Ginekol (Sofia) 42:33-36

19. Do TT (2006) Congenital muscular torticollis: current concepts and review of treatment. Curr Opin Pediatr 18:26-29

20. Dörner L, Fritsch MJ, Stark AM, Mehdorn HM (2007) Posterior fossa tumors in children: how long does it take to establish the diagnosis? Childs Nerv Syst 23:887-890

21. Drigo P, Carli G, Laverda AM (2000) Benign paroxysmal torticollis of infancy. Brain Dev 22:169-172

22. Dubousset J (1986) Torticollis in children caused by congenital anomalies of the atlas. J Bone Joint Surg Am 68:178-188

23. Eavey RD (1995) Microtia and significant auricular malformation. Ninety-two pediatric patients. Arch Otolaryngol Head Neck Surg 121:57-62

24. Ehret FW, Whelan MF, Ellenbogen RG, Cunningham ML, Gruss JS (2004) Differential diagnosis of the trapezoid-shaped head. Cleft Palate Craniofac J 41:13-19

25. Ferrari F, Cioni G, Einspieler C, Roversi MF, Bos AF, Paolicelli PB, Ranzi A, Prechtl HF (2002) Cramped synchronized general movements in preterm infants as an early marker for cerebral palsy. Arch Pediatr Adolesc Med 156:460-467

26. Greenberg MF, Pollard ZF (2000) Ocular plagiocephaly: ocular torticollis with skull and facial asymmetry. Ophthalmology 107:173-178

27. Greenes DS, Schutzman SA (1999) Clinical indicators of intracranial injury in head-injured infants. Pediatrics 104:861-867

28. Groenendaal F, Hukkelhoven C (2007) Fractures in full-term neonates. Ned Tijdschr Geneeskd 151:424

29. Guleryuz A, Bagdatoglu C, Duce MN, Talas DU, Celikbas H, Köksel T (2002) Grisel's syndrome. J Clin Neurosci 9:81-84

30. Gupta AK, Roy DR, Conlan ES, Crawford AH (1996) Torticollis secondary to posterior fossa tumors. J Pediatr Orthop 16:505-507
31. Hoeksma AF, ter Steeg AM, Nelissen RG, van Ouwerkerk WJ, Lankhorst GJ, de Jong BA (2004) Neurological recovery in obstetric brachial plexus injuries: an historical cohort study. Dev Med Child Neurol 46:76-83

32. Hsieh YY, Tsai FJ, Lin CC, Chang FC, Tsai CH (2000) Breech deformation complex in neonates. J Reprod Med 45: 933-935

33. Huang MH, Mouradian WE, Cohen SR, Gruss JS (1998) The differential diagnosis of abnormal head shapes: separating craniosynostosis from positional deformities and normal variants. Cleft Palate Craniofac J 35:204-211

34. Hutchison BL, Hutchison LA, Thompson JM, Mitchell EA (2004) Plagiocephaly and brachycephaly in the first two years of life: a prospective cohort study. Pediatrics 114:970-980

35. Hutchison BL, Thompson JM, Mitchell EA (2003) Determinants of nonsynostotic plagiocephaly: a case-control study. Pediatrics 112:e316

36. Kabbani H, Raghuveer TS (2004) Craniosynostosis. Am Fam Physician 69:2863-2870

37. Kane AA, Mitchell LE, Craven KP, Marsh JL (1996) Observations on a recent increase in plagiocephaly without synostosis. Pediatrics 97:877-885

38. Kaplan KM, Spivak JM, Bendo JA (2005) Embryology of the spine and associated congenital abnormalities. Spine J 5:564-576

39. Kumar V, Prabhu BV, Chattopadhayay A, Nagendhar MY (2003) Bilateral sternocleidomastoid tumor of infancy. Int $\mathrm{J}$ Pediatr Otorhinolaryngol 67:673-675

40. Lam MH, Wong GY, Lao TT (2002) Reappraisal of neonatal clavicular fracture. Relationship between infant size and risk factors. J Reprod Med 47:903-908

41. Littlefield TR, Saba NM, Kelly KM (2004) On the current incidence of deformational plagiocephaly: an estimation based on prospective registration at a single center. Semin Pediatr Neurol 11:301-304

42. Mulliken JB, Vander Woude DL, Hansen M, LaBrie RA, Scott RM (1999) Analysis of posterior plagiocephaly: deformational versus synostotic. Plast Reconstr Surg 103:371-380

43. Odding E, Roebroeck ME, Stam HJ (2006) The epidemiology of cerebral palsy: incidence, impairments and risk factors. Disabil Rehabil 28:183-191

44. Oguni H (2005) Symptomatic epilepsies imitating idiopathic generalized epilepsies. Epilepsia 46(Suppl 9):84-90

45. Palisano RJ, Snider LM, Orlin MN (2004) Recent advances in physical and occupational therapy for children with cerebral palsy. Semin Pediatr Neurol 11:66-77

46. Palmer FB (2004) Strategies for the early diagnosis of cerebral palsy. J Pediatr 145:S8-S11

47. Paysse EA, Coats DK (1997) Anomalous head posture with earlyonset homonymous hemianopia. J AAPOS 1:209-213

48. Peitsch WK, Keefer CH, LaBrie RA, Mulliken JB (2002) Incidence of cranial asymmetry in healthy newborns. Pediatrics 110:e72

49. Perlow JH, Wigton T, Hart J, Strassner HT, Nageotte MP, Wolk BM (1996) Birth trauma. A five-year review of incidence and associated perinatal factors. J Reprod Med 41:754-760

50. Persing J, James H, Swanson J, Kattwinkel J; American Academy of Pediatrics Committee on Practice and Ambulatory Medicine, Section on Plastic Surgery and Section on Neurological Surgery (2003) Prevention and management of positional skull deformities in infants. Pediatrics 112:199-202

51. Pollack IF, Losken HW, Fasick P (1997) Diagnosis and management of posterior plagiocephaly. Pediatrics 99:180-185

52. Pondaag W, Malessy MJ, van Dijk JG, Thomeer RT (2004) Natural history of obstetric brachial plexus palsy: a systematic review. Dev Med Child Neurol 46:138-144 
53. Rauschning W, Fredriksson BA, Wilander E (1982) Histomorphology of idiopathic and symptomatic popliteal cysts. Clin Orthop Relat Res 164:306-311

54. Reiners CH, Souid AK, Oliphant M, Newman N (2000) Palpable spongy mass over the clavicle, an underutilized sign of clavicular fracture in the newborn. Clin Pediatr (Phila) 39:695-698

55. Roche CJ, O’Malley M, Dorgan JC, Carty HM (2001) A pictorial review of atlanto-axial rotatory fixation: key points for the radiologist. Clin Radiol 56:947-958

56. Roovers EA, Boere-Boonekamp MM, Castelein RM, Zielhuis GA, Kerkhoff TH (2005) Effectiveness of ultrasound screening for developmental dysplasia of the hip. Arch Dis Child Fetal Neonatal Ed 90:F25-F30

57. Rosenbaum P (2006) Classification of abnormal neurological outcome. Early Hum Dev 82:167-171

58. Sönmez K, Türkyilmaz Z, Demiroğullari B, Ozen IO, Karabulut R, Bağbanci B, Başaklar AC, Kale N (2005) Congenital muscular torticollis in children. ORL J Otorhinolaryngol Relat Spec $67: 344-347$
59. Steendijk R (1980) Diagnostic and aetiologic features of idiopathic and symptomatic growth hormone deficiency in the Netherlands. A survey of 176 children. Helv Paediatr Acta $35: 129-139$

60. Turner A, Gavel G, Coutts J (2005) Vascular rings - presentation, investigation and outcome. Eur J Pediatr 164:266-270

61. van Vlimmeren LA, Helders PJ, van Adrichem LN, Engelbert RH (2004) Diagnostic strategies for the evaluation of asymmetry in infancy-a review. Eur J Pediatr 163:185-191

62. van Vlimmeren LA, van der Graaf Y, Boere-Boonekamp MM, L'Hoir MP, Helders PJ, Engelbert RH (2007) Risk factors for deformational plagiocephaly at birth and at 7 weeks of age: a prospective cohort study. Pediatrics 119:e408-e418

63. Williams CR, O’Flynn E, Clarke NM, Morris RJ (1996) Torticollis secondary to ocular pathology. J Bone Joint Surg Br 78:620-624

64. Wilson GN, Cooley WC (2000) Preventive management of children with congenital anomalies and syndromes. Cambridge University Press, Cambridge, UK, pp 80-83 